\title{
${ }^{131}$ I thyroid activity and committed dose assessment among family members of patients treated with radioactive iodine
}

\author{
K. Brudecki ${ }^{1}$ - A. Kluczewska-Gałka² $\cdot$ P. Zagrodzki ${ }^{3} \cdot$ B. Jarząb ${ }^{2} \cdot$ K. Gorzkiewicz ${ }^{1} \cdot$ T. Mróz $^{4}$
}

Received: 21 November 2019 / Accepted: 13 June 2020 / Published online: 20 June 2020

(c) The Author(s) 2020

\begin{abstract}
The main goal of the present study was estimation of an internal contamination of ${ }^{131} \mathrm{I}$ among family members of patients treated with radioactive iodine. Thyroid activity measurements of ${ }^{131} \mathrm{I}$ in examined volunteers were performed using a whole-body spectrometer at the institute of nuclear physics, Polish academy of sciences. During this research, 20 relatives of patients treated with ${ }^{131}$ I were examined: eight women and 12 men with an age in the range from 3 to 72 years. In the case of nine individuals, the activity of ${ }^{131} \mathrm{I}$ in the thyroid was below the detection limit, but among the remaining 11 individuals, the activity varied from $(9 \pm 3) \mathrm{Bq}$ up to $(1140 \pm 295) \mathrm{Bq}$. Subsequently, based on the measurements of thyroid ${ }^{131}$ I activities, the corresponding doses were assessed. The highest estimated effective dose reached $218 \mu \mathrm{Sv}$, while the thyroid equivalent dose was $2.4 \mathrm{mSv}$. In addition, the experimental data obtained were statistically analysed together with the results of surveys of the individuals participating in the study by means of correspondence analysis and nonparametric tests: Mann-Whitney, gamma, $\chi^{2}$ and Yule Phi coefficient. These analyses revealed relationships between ${ }^{131}$ I activities in the thyroids of the examined individuals and their housing conditions as well as consumption of meals prepared by the patients.
\end{abstract}

Keywords ${ }^{131} \mathrm{I} \cdot$ Family members $\cdot$ Whole body counting $\cdot$ Dosimetry

\section{Introduction}

Since the very beginning of nuclear medicine (the $30-40 \mathrm{~s}$ of the 20th century), ${ }^{131}$ I has been playing a key role. ${ }^{131} \mathrm{I}$ was discovered by Glenn Seaborg and John Livingood in 1938 at the University of California, Berkeley. The first reports about its application in medicine appeared less than eight years later, when Hertz and Roberts, and Seidlin and co-workers successfully applied ${ }^{131} \mathrm{I}$ in treatment procedures of Graves'

\section{K. Brudecki}

kamil.brudecki@ifj.edu.pl

1 Polish Academy of Sciences, Institute of Nuclear Physics, Radzikowskiego 152, 31-342 Kraków, Poland

2 Department of Nuclear Medicine and Endocrine Oncology Comprehensive Cancer Center, M. Skłodowska-Curie Memorial Institute of Oncology, Wybrzeże Armii Krajowej 15, 44-101 Gliwice, Poland

3 Department of Food Chemistry and Nutrition, Medical College Jagiellonian University, Medyczna 9, 30-688 Kraków, Poland

4 Institute of Physics, Jagiellonian University, Łojasiewicza 11, 30-348 Kraków, Poland disease and thyroid cancer (Hertz and Roberts 1946; Seidlin et al. 1946). Currently, ${ }^{131} \mathrm{I}$ is used in thyroid and wholebody scintigraphy, and in treatment of hyperthyroidism and thyroid cancer. In the case of thyroid disease, in Poland, single activities of ${ }^{131} \mathrm{I}$ administered to patients are in the range from $0.05 \mathrm{mCi}(1.85 \mathrm{MBq})$ in the case of thyroid scintigraphy, up to $250 \mathrm{mCi}(9.25 \mathrm{GBq})$ during cancer treatment.

The above-mentioned medical interventions like scintigraphy and hyperthyroidism treatment allow performing limited ambulatory care, which means that after the application of ${ }^{131} \mathrm{I}$, patients may return to their homes. In the case of thyroid cancer treatment, it is necessary to isolate patients in the hospital for a few days after ${ }^{131}$ I application (usually 3-5 days). In Polish hospitals, during this period, constant monitoring of the dose rate from the patient's body is performed. When the dose rate drops below $5 \mu \mathrm{Sv} \mathrm{h}^{-1}$ at a distance of $2 \mathrm{~m}$, the patient may qualify for discharge from hospital. Such a dose rate corresponds to an activity of about $400 \mathrm{MBq}$ accumulated in the patient's body. This activity level (400-600 MBq) is used as the patient discharge limit in most European Union member states (EURATOM 1997; ICRP 2004). Another criterion is the dose rate of radiation emitted from the patient's body. 
In many European countries (e.g., Germany, and in contrast to Poland) the dose rate limit is set at $3.5 \mu \mathrm{Sv} \mathrm{h}^{-1}$ (measured at a distance of $2 \mathrm{~m}$ from the patient) and the hospitalization period is set to at least 2 days. Different regulations are used in Japan, where the patient can be released from hospital if the ${ }^{131} \mathrm{I}$ activity in his body is less than $500 \mathrm{MBq}$ or the dose rate measured at a distance of $1 \mathrm{~m}$ is less than $30 \mu \mathrm{Sv} \mathrm{h}{ }^{-1}$. In the United States, patients' release criteria are defined by the US Nuclear Regulatory Commission (USNRC 1997a, b). In general, release criteria are based on physical half-life, activity or dose rate. Based on these criteria, the International Commission on Radiological Protection recommends patients to be released from hospital if their residual activity of ${ }^{131} \mathrm{I}$ is less than $800 \mathrm{MBq}$ (ICRP 2004). In addition, patients should receive basic instructions regarding radiological protection, which should be followed after returning home. In this context, the most important instructions for patients are isolation from other members of the family for about 2 weeks, lack of contact with children and pregnant women, utilization of their own toilet and kitchen utensils as well as special care for personal hygiene and caution when urinating.

However, there is a potential risk that patients may neglect or even totally desist obeying these radiological protection rules. So far, the approach to radiation protection of family members' patients treated with radioactive iodine was based only on the assessment of external doses (Mathieu et al. 1999; Pant et al. 2005; Kocovska et al. 2011a, b; Zehtabian et al. 2017). Nonetheless, ${ }^{131}$ I is being excreted from the patient's body (mainly in sweat and urine) and easily sublimes, which may cause a potential risk that it is inhaled relatives and accumulated in their thyroids. Consequently, the main goal of the present study was an estimation of internal contamination with ${ }^{131}$ I among family members of patients treated with radioactive iodine and assessment of corresponding radiation doses.

\section{Materials and methods}

\section{Volunteers}

In this study, 20 relatives of patients treated with ${ }^{131}$ I were examined: eight women and 12 men at an age in the range from 3 to 72 years. These individuals were family members of patients treated for hyperthyroidism (six cases) or thyroid cancer (14 cases). Predominantly, they were patients' partners or children (four children under 18 years of age). The study was approved by the Bioethics Committee at the Regional Chambers of Physicians and Dentists in Krakow, Poland (decision number 111/KBL/OIL/2015, dated 09.09.2015).

\section{${ }^{131}$ I activity measurements}

Thyroid activity measurements of ${ }^{131}$ I in examined volunteers were performed using the whole-body spectrometer at the Institute of Nuclear Physics, Polish Academy of Sciences. The shielding of the spectrometer was purposely designed allowing to place and measure the whole body of an adult person: the shielding is $2 \mathrm{~m}$ long, $1.2 \mathrm{~m}$ wide and $1.3 \mathrm{~m}$ high. The shield is made of steel from the 19th century, free from ${ }^{60} \mathrm{Co}$ traces to keep radiation background low, and the thickness of its walls is about $17 \mathrm{~cm}$, while its mass is about 18 tons (Mietelski et al. 2013).

The activity of ${ }^{131}$ I was measured using a low-background gamma-ray spectrometer equipped with an n-type germanium detector (HPGe, GMX-30190-P by Ortec with $30 \%$ relative efficiency). Data acquisition and analysis were performed using Canberra equipment and software (Multiport II, Genie-2000). Quantification of ${ }^{131}$ I activity in thyroids was carried out by measuring the $364.49 \mathrm{keV}$ gamma-line.

Calibration of the detector was performed with an adult human thyroid phantom containing an ${ }^{131}$ I solution with an activity of $6 \mathrm{kBq} \pm 0.6 \%$. The dimensions of the phantom are $5.5 \mathrm{~cm}$ long, $2.5 \mathrm{~cm}$ wide and $2 \mathrm{~cm}$ high. The average detector efficiency was estimated to be $(0.31 \pm 0.08) \%$. The estimated uncertainty is relatively high, namely $25 \%$, because it takes into account the large uncertainty due to the relative position of the thyroid gland and the detector (Kierepko et al. 2014). This high uncertainty of the efficiency propagates to a relatively high uncertainty of ${ }^{131} \mathrm{I}$ activity in the thyroid gland.

A single measurement lasted about $60 \mathrm{~min}$, and the detector was placed from 2 to $4 \mathrm{~cm}$ from thesurface of the neck. Typically, in the measurements a limit of detection (LOD) of about 4-6 Bq was achieved, depending on the measurement parameters described above. Measurements of ${ }^{131}$ I activity in relatives' thyroids were performed 7 days after discharge of patients from hospital.

\section{Questionnaire surveys}

Every person who took part in the study was asked to complete a questionnaire that consisted of four main parts. The first part included general questions about height, weight and gender, while the second part described frequency and character of interactions with the treated person. The third part focused on housing conditions like living in the city or on the countryside, living in a single-family house or in a flat, surface area of apartment, number of 
rooms or bathroom sharing with the patient. In the last part the participants were asked about their food habits (e.g., whether they consumed meals prepared by patient). Apart from anthropometric parameters, all other data from the questionnaire were strictly categorized by assigning them either logical values: yes $=1$ or no $=0$ (for dichotomous variables), or more numerically ordered values (for multilevel variables), thus bringing about dichotomous and multilevel categorical parameters, respectively.

\section{Statistical approach}

To quantify any dependencies between the investigated parameters, 20 complete survey forms were studied with a statistical correspondence analysis (CA) method. The nominal or ordinal data from the questionnaire (the dichotomous and multilevel categorical parameters mentioned above) were gathered in a contingency table together with the thyroid activities measured in the individuals. The results on ${ }^{131}$ I activity were then transformed into an ordinal scale (four categories) according to the following algorithm: (1) low activities ( $<11 \mathrm{~Bq}$ ), (2) moderate activities $(\geq 11 \mathrm{~Bq}$ and $<150 \mathrm{~Bq}),(3)$ elevated activities $(\geq 150 \mathrm{~Bq}$ and $<600 \mathrm{~Bq}$ ), (4) highly elevated values ( $>1100 \mathrm{~Bq}$ ). All these parameters formed a multidimensional space of original scores. The analyses of coordinates of the dichotomous and multilevel categorical parameters in the coordinate system of the CA model, generated in the reduced (two-dimensional) space determined by the first two new dimensions of this model, allowed to reveal the structure of associations between parameters. In this work, CA was constructed under the condition that its first two dimensions should explain at least $50 \%$ of the total inertia in the original set of parameters. Thus, the parameters or their categories with the lowest quality of representation were subsequently discarded as well as associations in the CA model depending only on single coincidence. Those parameters with large absolute values of their coordinates $(>0.3)$ in the CA model were assumed to be associated with one another. To express the strength of bivariate associations, for the pairs of associated parameters, the algebraic products of their corresponding coordinates and cosine of the corresponding angle were calculated (these coefficients are called the association weights). The "corresponding angle" was defined as the angle determined by two lines connecting the origin with coordinates of both parameters on the CA coordinates plot. Apart from CA, the gamma correlations $\left(R_{\gamma}\right)$ were computed for the pairs of categorical multilevel variables, while for dichotomous variables the $\chi^{2}$ test and Yule Phi coefficient were calculated. For thyroid activities, categories (2), (3) and (4) were combined, thus, this variable became a dichotomous one. The difference of thyroid activities (categorized into four groups) between family members of patients either with cancer or with hyperthyroidism was checked using the Mann-Whitney $U$ test. To estimate the mean values of thyroid activities in the above-mentioned two groups of family members, data were transformed in logarithms and retransformed after calculation, because the parameter had a non-Gaussian distribution. Therefore, the data are shown as mean and confidence interval. In the calculations, the data below the LOD were substituted with the value of $\mathrm{LOD} \times 2^{-0.5}$.

The statistical analyses were carried out using the STATISTICA v. 12 package (Statsoft, Tulsa, OK, USA) and the software delivered by MP System Co. (Chrzanów, Poland). The latter was used to calculate correlation weights for the pairs of parameters in the CA model.

\section{Doses estimation}

In the case of individuals with detected ${ }^{131} \mathrm{I}$ in the thyroid gland, complete uptake of ${ }^{131} \mathrm{I}$ by the respiratory system as well as its activities in other organs were calculated. Calculations were based on the iodine biokinetics model developed by Leggett (Leggett 2010, 2017) in combination with the Human Respiratory Tract Model (ICRP 1994, 2002) and the Gastrointestinal Tract Model (ICRP 1979) developed by the International Commission on Radiological Protection (ICRP). For computer modeling, the SAAM II software from Epsilon Group was used (Barrett et al. 1998). The method used to calculate radiation doses was presented in detail in previous papers (Li 2018; Brudecki et al. 2014, 2017a, b, 2018a, b, 2019).

\section{Results and discussion}

In the present study, 20 individuals, i.e., relatives of patients treated with ${ }^{131} \mathrm{I}$, were examined. Results above the detection limit were obtained in 11 cases (55\%), and they were in the range $(9 \pm 3) \mathrm{Bq}$ up to $(1140 \pm 295) \mathrm{Bq}$. The exact results are presented in Table 1 . These individuals were family members of patients treated for hyperthyroidism (six cases) or thyroid cancer (14 cases). Among the first group, results above detection limit were achieved for four individuals $(67 \%)$, and the mean 131I activity for them was $41.7 \mathrm{~Bq}$ with a $95 \%$ confidence interval of $(4.6 ; 376.0) \mathrm{Bq}$. Values above the detection limit in the second group were observed in seven cases (50\%) with an average value $14.7 \mathrm{~Bq}$ and a 95\% confidence interval of $(2.3 ; 94.5) \mathrm{Bq}$.

As can be also inferred from Table 1, four children and 16 adults took part in this study. In the group of adults, an activity of ${ }^{131}$ I above detection limit was found in ten $(62.5 \%)$ of the examined individuals. In these individuals, measured activities ranged from $(9 \pm 3) \mathrm{Bq}$ up to $(1140 \pm 295) \mathrm{Bq}$. In the group of children, in one case (25\%) the activity of ${ }^{131} \mathrm{I}$ 
Table $1{ }^{131}$ I thyroid activity among family members of patients treated with radioactive iodine (thyroid activity uncertainties were calculated by means of uncertainty propagation method)

\begin{tabular}{|c|c|c|c|c|}
\hline Code & Gender & $\begin{array}{l}\text { Personal relation- } \\
\text { ship with patients } \\
\text { treated with }{ }^{131} \mathrm{I}\end{array}$ & Type of treatment & $\begin{array}{l}{ }^{131} \text { I thyroid } \\
\text { activity } \\
{[\mathrm{Bq}]}\end{array}$ \\
\hline A1 & M & Husband & Thyroid cancer & $9 \pm 3$ \\
\hline A2 & M & Son & Thyroid cancer & $<4$ \\
\hline A3 & $\mathrm{F}$ & Daughter & Hyperthyroidism & $51 \pm 14$ \\
\hline A4 & M & Husband & Thyroid cancer & $<5$ \\
\hline A5 & $\mathrm{F}$ & Wife & Thyroid cancer & $341 \pm 88$ \\
\hline A6 & M & Husband & Hyperthyroidism & $1140 \pm 295$ \\
\hline A7 & $\mathrm{F}$ & Daughter & Thyroid cancer & $20 \pm 6$ \\
\hline A8 & M & Husband & Hyperthyroidism & $98 \pm 25$ \\
\hline A9 & M & Husband & Thyroid cancer & $151 \pm 39$ \\
\hline A10 & $\mathrm{F}$ & Wife & Thyroid cancer & $10 \pm 3$ \\
\hline A11 & $\mathrm{F}$ & Sister & Thyroid cancer & $<4$ \\
\hline A12 & M & Husband & Thyroid cancer & $<4$ \\
\hline A13 & $\mathrm{F}$ & Wife & Thyroid cancer & $557 \pm 144$ \\
\hline A14 & M & Husband & Hyperthyroidism & $72 \pm 19$ \\
\hline A15 & M & Son & Hyperthyroidism & $<5$ \\
\hline A16 & M & Husband & Hyperthyroidism & $<6$ \\
\hline U1 & $\mathrm{F}$ & Daughter & Thyroid cancer & $58 \pm 15$ \\
\hline $\mathrm{U} 2$ & M & Son & Thyroid cancer & $<10$ \\
\hline U3 & $\mathrm{F}$ & Daughter & Thyroid cancer & $<11$ \\
\hline U4 & M & Son & Thyroid cancer & $<5$ \\
\hline
\end{tabular}

$A$, adults, $U$, underage, $M$, male, $F$, female

in the thyroid was above the detection limit and reached $(58 \pm 15) \mathrm{Bq}$. The difference in the number of results above detection limit-25\% vs. $62.5 \%$ - as well as the difference in maximum activities $(51 \pm 14 \mathrm{~Bq}$ vs. $1140 \pm 295 \mathrm{~Bq})$ observed among children and adults might be explained by an increased concern about the safety of children in all aspects of everyday life.

Interestingly, the maximum measured activity reached, $1140 \pm 295 \mathrm{~Bq}$, is relatively high. For comparison, in a separate study it was shown that the maximum activity of ${ }^{131} \mathrm{I}$ in the thyroid of medical staff who work with radioiodine on a daily basis reached only 217-457 Bq (Brudecki et al. 2017a,
$2018 b)$. The reason for such a high ${ }^{131}$ I activity in the thyroid of the husband of a female patient (see Table 1) may be the fact that the treated patient was bedridden and in need of continuous care by the tested relative.

As mentioned earlier, the measured ${ }^{131}$ I activities were statistically analysed along with the results of surveys of the individuals participating in the study, by means of CA and nonparametric tests: Mann-Whitney, gamma, $\chi^{2}$ and Yule Phi coefficient. The results are summarized in Tables 2, 3

Based on the performed analysis it can be concluded that the level of ${ }^{131}$ I activity in the thyroid of the examined individuals is primarily affected by their housing conditions. The gamma correlation analysis allowed to quantify the relationship between thyroid activity and the number of rooms in the apartment $\left(R_{\gamma}=-0.767, p<0.05\right)$. Next, $\chi^{2}$ and Yule Phi tests suggested concomitance between ${ }^{131}$ I activity in the thyroid and the following parameters: living in a city or on the countryside, the surface area of the apartment, consumption of meals prepared by the patient, living in a single-family house or in a flat, as well as sharing a bathroom with the patient (Table 2). This means that the ${ }^{131}$ I activity depends on whether the patients and their relatives live in a city or on the countryside. Specifically, it was found that ${ }^{131} \mathrm{I}$ activity in thyroids of relatives living in the city was higher than that of relatives living on the countryside. This could be explained taking into consideration that people in cities have typically less living space available than people on the countryside (for example in terms of surface area of the rooms,

Table 3 Association weights based on the correspondence analysis model [Thyroid activity III - elevated activities $(\geq 150$ and $<600 \mathrm{~Bq})$, Thyroid activity IV—-highly elevated values (>1100 Bq)]

\begin{tabular}{lll}
\hline Pairs of associated parameters & weight \\
\hline Thyroid activity IV & $\begin{array}{l}\text { Consumption of meals prepared by } \\
\text { patient }\end{array}$ & 0.96 \\
Thyroid activity III & $\begin{array}{l}\text { Number of rooms in apartment } \\
\text { Thyroid activity IV }\end{array}$ & Bathroom sharing with the patient \\
Thyroid activity IV & Frequent contact with patients & 0.87 \\
\hline
\end{tabular}

Table 2 Results of statistical analyses for dichotomous variables

\begin{tabular}{llrcc}
\hline Pairs of associated parameters & $\chi^{2}$ value & $\begin{array}{l}\text { Signifi- } \\
\text { cance level } \\
(p)\end{array}$ & Yule phi coefficient \\
\hline Thyroid activity & Living in city or in countryside & 5.05 & 0.025 & 0.503 \\
Thyroid activity & Surface area ${ }^{\text {a }}$ of apartment & 5.09 & 0.024 & -0.504 \\
Thyroid activity & Consumption of meals prepared by patient & 7.01 & 0.008 & 0.592 \\
Thyroid activity & living in single-family house or in flat & 8.81 & 0.030 & 0.664 \\
Thyroid activity & Bathroom sharing with the patient & 13.39 & 0.000 & 0.818 \\
\hline
\end{tabular}

${ }^{a}$ categorized sum of surfaces of all floors 
number of bathrooms). Moreover, higher ${ }^{131}$ I activities were observed in relatives living in flats (as compared to those living in single family houses), as well as in the situations when the meals were prepared by patients and the bathroom was shared with them. Conducted CA analyses confirmed the above-mentioned findings, and in addition, revealed a connection between ${ }^{131}$ I activity in relatives' thyroid and the frequency of their contacts with the patients (Table 3).

The difference in thyroid activities of family members of patients either with cancer or hyperthyroidism was not statistically significant. However, the number of examined individuals was low and, consequently, one should treat this result with caution.

The highest observed activity in the thyroid $(1140 \pm 295 \mathrm{~Bq})$ corresponds to an effective dose of only $218 \mu \mathrm{Sv}$, while the thyroid equivalent dose was $2.4 \mathrm{mSv}$. In the group of children, the maximum effective dose and thyroid equivalent dose reached $13 \mu \mathrm{Sv}$ and $0.16 \mathrm{mSv}$, respectively. These doses are relatively low, keeping in mind that the maximum effective dose of $218 \mu \mathrm{Sv}$ is only about $9 \%$ of the mean annual effective dose due to natural radiation sources in Poland, which may suggest that there will be no discernible negative consequences for the health of the examined individuals. In addition, the estimated doses are also significantly lower than the external doses found in other studies for relatives of patients treated with ${ }^{131} \mathrm{I}$ (Mathieu et al. 1999; Pant et al. 2005; Kocovska et al. 2011a, b; Zehtabian et al. 2017).

\section{Conclusions}

So far, the issue of internal contamination was mainly associated with people who work with open radioactive sources on a daily basis (e.g., medical staff). The current study showed that internal contamination may also affect relatives of patients treated with radiopharmaceuticals. Even though ${ }^{131}$ I activities in thyroids of the investigated relatives could be detected in some cases (up to about $1000 \mathrm{~Bq}$ ), the related doses are rather low, i.e., less than $218 \mu \mathrm{Sv}$, which is less than about $9 \%$ of the mean annual effective dose due to natural radiation sources in Poland, which is about $2.48 \mathrm{mSv}$ per year (Janik and Tokonami 2009). In the light of current knowledge it is concluded that internal doses received by family members of patients treated with ${ }^{131}$ I will not result in any discernable negative health consequences.

In addition, the results of the statistical analyses performed in the present study revealed relationships between ${ }^{131}$ I activities in the thyroids of some of the investigated individuals and their housing conditions (number of rooms, surface area of apartments, whether or not a bathroom is shared with a patient discharged from hospital after treatment with ${ }^{131} \mathrm{I}$ ) as well as consumption of meals prepared by the patient. Knowledge of such facts may lead to an improvement in the radiological protection of patients' relatives in the future.

Acknowledgements This study was funded by the National Science Center, Poland (Grant number 2014/15/B/NZ7/00925).

\section{Compliance with ethical standards}

Conflict of interest The authors declare that they have no conflict of interest.

Human and animal rights All procedures performed in studies involving human participants were in accordance with the ethical standards of the institutional and/or national research committee and with the 1964 Helsinki Declaration and its later amendments or comparable ethical standards.

Informed consent Informed consent was obtained from all individual participants included in the study.

Open Access This article is licensed under a Creative Commons Attribution 4.0 International License, which permits use, sharing, adaptation, distribution and reproduction in any medium or format, as long as you give appropriate credit to the original author(s) and the source, provide a link to the Creative Commons licence, and indicate if changes were made. The images or other third party material in this article are included in the article's Creative Commons licence, unless indicated otherwise in a credit line to the material. If material is not included in the article's Creative Commons licence and your intended use is not permitted by statutory regulation or exceeds the permitted use, you will need to obtain permission directly from the copyright holder. To view a copy of this licence, visit http://creativecommons.org/licenses/by/4.0/.

\section{References}

Barrett PHR, Bell BM, Cobelli C, Golde H, Schumitzky A, Vicini P, Foster DM (1998) SAAM II: simulation, analysis, and modeling software for tracer and pharmacokinetic studies. Metabolism 47:484-492

Brudecki K, Li WB, Meisenberg O, Tschiersch J, Hoeschen C, Oeh U (2014) Age-dependent inhalation doses to members of the public from indoor short-lived radon progeny. Radiat Environ Biophys 53:535-549

Brudecki K, Kowalska A, Zagrodzki P, Szczodry A, Mroz T, Janowski P, Mietelski JW (2017a) Measurement of ${ }^{131}$ I activity in thyroid of nuclear medical staff and internal dose assessment in a Polish nuclear medical hospital. Radiat Environ Biophys 56:19-26

Brudecki K, Szufa K, Mietelski JW (2017b) ${ }^{131}$ I age-dependent inhalation dose in southern Poland from Fukushima accident. Radiat Environ Biophys 56(1):9-17

Brudecki K, Szczodry A, Mróż T, Kowalska A, Mietelski JW (2018a) Measurement of ${ }^{131} \mathrm{I}$ activity in air indoor Polish nuclear medical hospital as a tool for an internal dose assessment. Radiat Environ Biophys 57(1):77-82

Brudecki K, Kluczewska-Gałka A, Mróz T, Jarząb B, Zagrodzki P, Janowski P (2018b) ${ }^{131}$ I internal contamination and committed dose assessment among nuclear medicine medical personnel. Radiat Prot Dosimetry 179(3):275-281 
Brudecki K, Borkowska E, Gorzkiewicz K, Kostkiewicz M, Mróz T (2019) ${ }^{99 \mathrm{~m}} \mathrm{Tc}$ activity concentrations in room air and resulting internal contamination of medical personnel during ventilationperfusion lung scans. Radiat Environ Biophys 58(3):469-475

European Atomic Energy Community (Euroatom) (1997) Radiation protection 97. Radiation protection following iodine - 131 therapy (Exposure due to out - patients or discharged in-patients). EURATOM, Brussels

Hertz S, Roberts A (1946) Radioactive iodine in the study of thyroid physiology; the use of radioactive iodine therapy in hyperthyroidism. J Am Med Assoc 131:81-86

International Commission of Radiological Protection (ICRP) (1979) Limits for intakes of radionuclides by workers. ICRP Publication 30 (Part 1). Ann ICRP 2(3-4)

International Commission of Radiological Protection (ICRP) (1994) The human respiratory tract model for radiological protection. ICRP Publication 66. Ann ICRP 24(1-3)

International Commission of Radiological Protection (ICRP) (2002) Guide for the practical application of the ICRP human respiratory tract model. ICRP Supporting Guidance 3. Ann ICRP 32(1-2)

International Commission of Radiological Protection (ICRP) (2004) Release of patients after therapy with unsealed radionuclides. ICRP Publication 94. Ann ICRP 34(2)

Janik M, Tokonami S (2009) Natural and artificial sources of radioactivity in Poland. Jpn J Health Phys 44(1):116-121

Kierepko R, Janowski P, Grochowska M (2014) Variation of counting efficiency in determination of ${ }^{131} \mathrm{I}$ activity in the thyroid gland as a result of its position relative to the detector. J Radioanal Nucl Chem 300:825-828

Kocovska MZ, Vaskova O, Majstorov V, Kuzmanovska S, Gjorceva DP, Jokic VS (2011a) Effective doses to family members of patients treated with radioiodine-131. J Phys Conf Ser 317:12-12

Kocovska MZ, Vaskova O, Majstorov V (2011b) RADAR calculated vs. TLD effective doses to family members of thyroid cancer patients treated with iodine 131. Maced J Med Sci 4:12-16

Leggett RW (2010) A physiological systems model for iodine for use in radiation protection. Radiat Res 174:496-516
Leggett RW (2017) An age-specific biokinetic model for iodine. J Radiol Prot 37:864-882

Li WB (2018) Internal dosimetry—a review of progress. Jpn J Health Phys 53(2):72-99

Mathieu I, Caussin J, Smeesters P, Wambersie A, Beckers C (1999) Recommended restrictions after ${ }^{131}$ I therapy: measured doses in family members. Health Phys 76:129-136

Mietelski JW, Janowski P, Kierepko R, Hajduk R, Bogacz J, Jurkowski J, Ochab E (2013) A Whole-Body Spectrometer (WBS) at the Institute of Nuclear Physics, Kraków: design and results for Polish citizens visiting Japan during the Fukushima accident. Nukleonika 58(4):519-525

Pant GS, Sharma SK, Bal CS, Kumar R, Rath GK (2005) Radiation dose to family members of hyperthyroidism and thyroid cancer patients treated with 131I. Radiat Prot Dosim 118:22-27

Seidlin SM, Marinelli LD, Oshry E (1946) Radioactive iodine therapy; effect on functioning metastases of adenocarcinoma of the thyroid. J Am Med Assoc 132(14):838-847

United States Nuclear Regulatory Commission (USNRC) (1997a) Regulatory analysis on criteria for the release of patients administered radioactive material. Final report. USNRC, Washington

United States Nuclear Regulatory Commission (USNRC) (1997b) Regulatory Guide 8.39. Release of patients administered radioactive materials. USNRC, Washington

Zehtabian M, Dehghan N, Danaei Ghazanfarkhani M, Haghighatafshar M, Sina S (2017) Measurement of the dose to the family members taking care of thyroid cancer patients undergoing I-131 therapy in nuclear medicine using TLD-100. Radiat Prot Dosim 174:541-544

Publisher's Note Springer Nature remains neutral with regard to jurisdictional claims in published maps and institutional affiliations. 